\title{
Análise da governança dos recursos hídricos na bacia hidrográfica do Rio Paraíba
}

No presente trabalho foi analisada a articulação da gestão dos recursos hídricos com a gestão urbana, considerando como caso de estudo a bacia hidrográfica do Rio Paraíba, à luz dos princípios da governança da OECD a fim de definir diretrizes e recomendações para boa governança. Considerando a integração do território como elemento fundamental para uma boa gestão dos recursos hídricos, foi percebido que embora no Brasil existem legislações avançadas (como a Política Nacional de Recursos Hídricos) ainda existem lacunas que dificultam a articulação da gestão das águas com o território, pois suas políticas públicas foram pensadas e implementadas como se as dinâmicas fossem independentes. Neste sentido, foram propostas diretrizes, baseadas nos princípios da governança da OECD, para o preenchimento das lacunas existentes. Assim, foi identificado a necessidade de melhores estratégias na elaboração das políticas, considerando que embora se tenham divisões políticas-administrativas diferentes, o território e os recursos são os mesmos. E que, as tomadas de decisão, seja no âmbito da bacia ou do município, precisam ser capazes de refletir a real dinâmica do território, onde os processos ocorridos nas cidades, tem impactos significativos na dinâmica da bacia hidrográfica, requerendo assim um maior comprometimento e envolvidos dos atores de ambas as gestões.

Palavras-chave: Recursos Hídricos; Gestão Urbana; Espaços Participativos; Saneamento; Governança.

\section{Analysis of water resources governance in the Paraiba River basin}

\begin{abstract}
This article aims to analyze the articulation of water resources management with urban management, considering as case study the Paraiba river basin, the OECD governance principles were applied to define guidelines and recommendations for good governance. We discuss the integration on the territory as a fundamental element for a good management of water resources and despite the advanced legislations in Brazil, some gaps need to be overcome for a better articulation between territory and water management, for its public policies were conceived and implemented as if the dynamics were independent. In this regard, guidelines have been proposed based on OECD governance principles, to fill the gaps between urban and water resources management. Thus, the need for better policymaking strategies was identified, considering that while the political-administrate divisions different, the territory and resources are the same. And, decisionmaking process, whether in the basin or in the municipality be able to reflect a true territory use, the processes occur in cities, have effects in the river basin, thus requesting greater commitment and participation of the stakeholders.
\end{abstract}

Keywords: Water Resources; Urban Management; Public Participation; Sanitation; Governance.

Topic: Planejamento, Gestão e Políticas Públicas Ambientais

Reviewed anonymously in the process of blind peer
Received: 10/08/2019

Approved: 28/09/2019
Ester Luiz de Araújo Grangeiro (iD

Universidade Federal de Campina Grande, Brasil

http://lattes.cnpq.br/6990916562687541

http://orcid.org/0000-0002-1915-4638

esterluiz.eng@gmail.com

Marcia Maria Rios Ribeiro

Universidade Federal de Campina Grande, Brasil

http://lattes.cnpq.br/4564679783610341

http://orcid.org/0000-0002-3446-6752

marcia.ribeiro@ufcg.edu.br

Livia Izabel Bezerra de Miranda

Universidade Federal de Campina Grande, Brasil

http://lattes.cnpq.br/2698541099194056

http://orcid.org/0000-0003-3741-4736

liviaibmiranda@gmail.com
Referencing this:

GRANGEIRO, E. L. A.; RIBEIRO, M. M. R.; MIRANDA, L. I. B.. Análise da governança dos recursos hídricos na bacia hidrográfica do Rio Paraíba. Revista Ibero Americana de Ciências Ambientais, v.10, n.5, p.314330, 2019. DOI: http://doi.org/10.6008/CBPC21796858.2019.005.0028

DOI: 10.6008/CBPC2179-6858.2019.005.0028 


\section{INTRODUÇÃO}

Os recursos hídricos de uma região estão ligados à diversos setores e diferentes escalas geográficas e temporais. No entanto, em muitos casos, as fronteiras hidrográficas e os perímetros administrativos municipais não coincidem, sendo assim um importante desafio para a gestão integrada das águas e do território. Outro desafio são as transformações ocorridas nas cidades, sobretudo diante do rápido processo de urbanização, que geram uma grande pressão sobre os recursos hídricos assim uma adequada integração entre a água e o planejamento do uso do solo é necessária, tanto para permitir que os sistemas urbanos continuem a existir quanto para reduzir o impacto nos recursos hídricos em escala regional (BARRON et al., 2017, MITCHELL et al., 2015, SERRAO-NEUMANN et al., 2017).

As ações desenvolvidas no âmbito de uma política setorial têm potencial de influenciar diretamente outro setor, neste sentido, alguns autores (RUNHAAR et al., 2014; BROWNE et al., 2017) destacam o conceito de integração de políticas ambientais como uma alternativa a gestão fragmentada e com setores desconectados, pois, aborda as preocupações ambientais nas políticas de agricultura, urbana, transportes, entre outras, no sentido de promover uma integração de políticas gerando benefícios mútuos aos setores envolvidos.

No Brasil, a completa integração entre a gestão dos recursos hídricos e a gestão urbana ainda é um desafio, embora a legislação sinalize para a necessidade da mesma. É fato que muitos problemas de gestão de recursos surgem a partir de falhas na governança assim, uma melhor compreensão sobre governança é essencial para a gestão dos recursos naturais, entre eles os recursos hídricos.

A gestão dos recursos hídricos no Brasil é de domínio da União e dos Estados, conforme a Constituição Federal de 1988, mas influencia diretamente a qualidade de vida urbana, visto que os serviços de saneamento básico deficientes podem comprometer a salubridade ambiental e a vida humana. A gestão urbana é de competência do município e deve ser realizada em nível de território municipal. No âmbito da gestão urbana está o planejamento do uso do solo, a mobilidade urbana, habitação e o saneamento.

Todavia, é importante notar que a gestão do saneamento é diretamente influenciada pela gestão dos recursos hídricos na bacia hidrográfica. E que, embora as ações municipais sobre os recursos hídricos se encontrem voltadas prioritariamente para medidas de saneamento básico, elas se limitam ao input/output na bacia hidrográfica, ignorando seus fluxos.

Nesse contexto, o conceito de governança da água surge como uma possibilidade interessante no âmbito da integração das gestões. A governança da água pode ser entendida, de modo geral, como os atores sociais e aos agentes governamentais responsáveis por uma boa gestão da água, assim como às instituições, regras e procedimentos para tomada de decisão quanto às formas de uso dos recursos (CAMPOS et al., 2010).

Assim, o presente trabalho analisou os princípios da governança multinível da OECD (Organization for Economic Co-operation and Development) com o objetivo de identificar em que aspectos a governança dos recursos hídricos, através de suas políticas e espaços de participação, deverá interagir com a gestão do espaço urbano e o território municipal para proporcionar uma adequada governança dos recursos hídricos e 
quais as estratégias para atender aos requisitos dessa governança. A análise foi realizada para a Bacia Hidrográfica do Rio Paraíba.

\section{METODOLOGIA}

A metodologia foi estruturada em cinco etapas: 1) Caracterização da área de estudo; 2) Análise documental do aparato jurídico-institucional e espaço de participação no processo de governança dos recursos hídricos; 3) Identificação das falhas no sistema de gestão; 4) Diagnóstico da governança multinível na área estudada; e 5) Proposição de diretrizes para a boa governança.

\section{Caracterização da área de estudo: Bacia hidrográfica do Rio Paraíba}

A bacia hidrográfica do Rio Paraíba (Figura 1) está completamente inserida nos limites do estado da Paraíba, sendo a segunda maior Bacia Hidrográfica do Estado da Paraíba e um dos sistemas hidrográficos mais importantes do semiárido nordestino. A Bacia Hidrográfica do rio Paraíba compreende $35,7 \%$ do território estadual, drenando uma área de $20.127,17 \mathrm{~km}^{2}$.

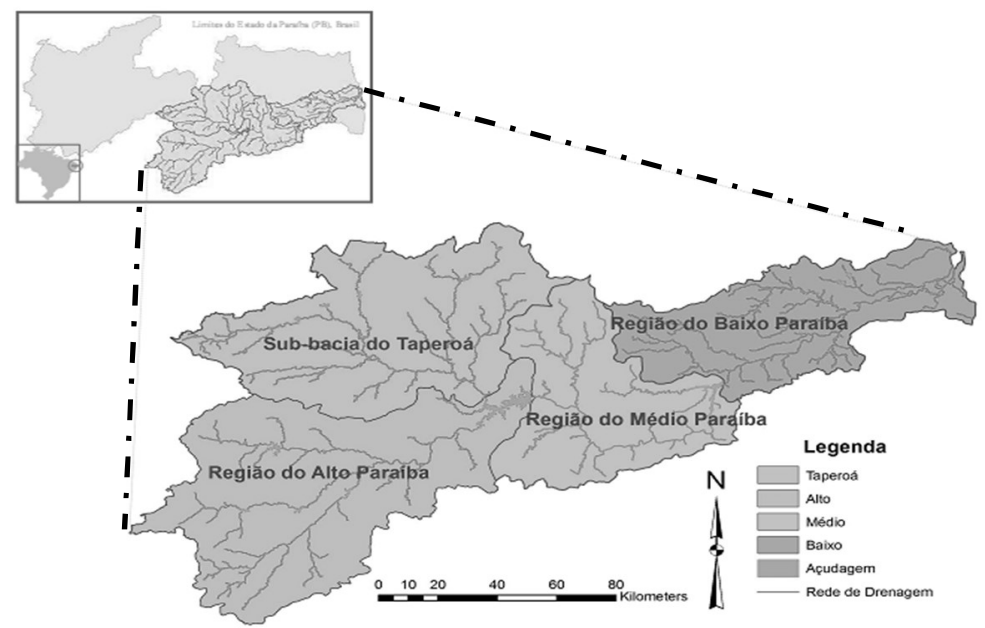

Figura 1: Localização da bacia hidrográfica do Rio Paraíba no estado da Paraíba. Fonte: Rêgo et al. (2013).

A Bacia Hidrográfica do Rio Paraíba é composta por oitenta e cinco municípios, entre eles, as duas cidades mais importantes do Estado da Paraíba (João Pessoa - capital do Estado, e Campina Grande - centro econômico, educacional e tecnológico do Nordeste). Os seus limites hidrográficos são divididos em quatro sub-bacias: a Bacia Hidrográfica do Rio Taperoá e as Bacias Hidrográficas do Alto, Médio e Baixo Paraíba e integra as mesorregiões da Borborema, do Agreste e do Litoral paraibano.

A Região do Alto Curso está localizada na parte sudoeste do planalto da Borborema, faz fronteira ao norte com a bacia do Taperoá, ao sul e a oeste com o Estado de Pernambuco e a leste com a Região do Médio Curso do rio Paraíba. A Região do Médio Curso situa-se ao sul do planalto da Borborema, limita-se ao sul, com o Estado de Pernambuco, a oeste, com a bacia do Taperoá e com a Região do Alto Curso (RIBEIRO, 2016).

A Região do Baixo Curso do rio Paraíba está localizada na parte litorânea do Estado da Paraíba. Limitase ao sul com a sub-bacia do Gramame e com o Estado de Pernambuco, ao norte com a bacia do Mamanguape e Miriri, a oeste com a Região do Médio Curso do rio Paraíba e a leste com o Oceano Atlântico. 
A sub-bacia do rio Taperoá está localizada na parte central do estado da Paraíba. Limita-se com as sub-bacias do Espinharas e do Seridó a oeste, com a Região do Alto Curso do rio Paraíba ao sul, com as bacias do Jacú e Curimataú ao norte, e com a Região do Médio Curso do rio Paraíba a leste (RIBEIRO, 2016).

\section{Análise documental do aparato jurídico-institucional e espaço de participação no processo de governança dos recursos hídricos}

A análise documental do aparato jurídico-institucional foi realizada considerando as políticas de recursos hídricos. A análise foi realizada a partir de princípios previamente selecionados e analisados para cada item (Tabela 1). Para a análise documental, os documentos analisados foram: Lei 9.433/1997 - Lei das Águas e Lei 6.308/1996 - Política Estadual de Recursos Hídricos.

Tabela 1: Documentos da gestão dos recursos hídricos e os respectivos princípios analisados.

\begin{tabular}{|l|l|}
\hline Documentos analisados & Princípios analisados \\
\hline Lei 9.433/1997 - PNRH & Princípio 1 (Papeis e Responsabilidades) \\
Lei ${ }^{\circ}$ 6.308/1996 e Lei no 8.446/2007 - PERH & $\begin{array}{l}\text { Princípio } 2 \text { (Escalas apropriadas) } \\
\text { Princípio 5 (Dados e informação consistentes) } \\
\text { Princípio } 7 \text { (Quadros regulatórios sólidos) } \\
\text { Princípio 9 (Integridade e transparência) }\end{array}$ \\
\hline Atas das reuniões do Comitê de Bacia Hidrográfica do Rio Paraíba. & $\begin{array}{l}\text { Princípio 4 (Capacitação das autoridades responsáveis) } \\
\text { Princípio } 5 \text { (Dados e informação consistentes) }\end{array}$ \\
& $\begin{array}{l}\text { Princípio 8 (Práticas inovadoras) } \\
\text { Princípio 9 (Integridade e transparência) }\end{array}$ \\
& $\begin{array}{l}\text { Princípio 10 (Comprometimento das partes interessadas) } \\
\text { Princípio 11(Compromissos equilibrados) } \\
\text { Princípio 12 (Monitorização e avaliação) }\end{array}$ \\
\hline
\end{tabular}

A análise dos espaços de participação foi realizada através da análise documental das atas das reuniões do comitê de bacia hidrográfica do rio Paraíba. As atas analisadas foram dos anos 2007, 2008, 2009, 2010, 2011, 2012, 2014, 2015, 2016 e 2017.

\section{Diagnóstico da governança multinível na área estudada e Identificação das falhas no sistema de gestão}

Para o diagnóstico, procurou-se identificar se e como os princípios institucionais da OECD (2015) estão contemplados nos documentos que estabelecem as regras da governança dos recursos hídricos do caso de estudo. Foi igualmente investigado como de fato essas regras são implantadas, através da análise das atas das reuniões. As etapas de diagnóstico da governança multinível e identificação das falhas no sistema de gestão de recursos hídricos foram realizadas através da análise dos requisitos para atendimento dos princípios da OECD e da existência destes nos documentos analisados. Na etapa de diagnóstico, quando aqueles princípios foram identificados, foi considerado como dispositivo para a governança e, quando não, isso foi considerando como falha.

\section{Proposição de diretrizes para a boa governança}

As diretrizes para a boa governança foram propostas a partir da análise das políticas e das atas das reuniões do Comitê de Bacia Hidrográfica do rio Paraíba, sob o ponto de vista dos princípios escolhidos, e procuram preencher as lacunas (falhas) identificadas na etapa anterior. As diretrizes foram estabelecidas 
buscando a boa governança dos recursos hídricos, sob à luz dos princípios da governança da OECD.

\section{RESULTADOS E DISCUSSÃO}

As duas principais crises hídricas, ocorridas na área de estudo dessa pesquisa e que causaram sérios impactos na área urbana, foram analisadas por diversos autores, entre eles, Rêgo et al. (2001), o qual concluiu que a principal causa da primeira grande crise hídrica no sistema estudado, foi a completa ausência de gerenciamento da bacia hidrográfica e, mais especificamente, no manejo do reservatório que abastece o município de Campina Grande e região. Galvão et al. (2001) que apresentam como causa da primeira crise do reservatório Epitácio Pessoa a gestão inadequada de seus recursos hídricos, como, por exemplo, a retirada de água maior do que a disponibilidade do reservatório.

Silva (2014) analisou o mesmo sistema, através de princípios de governança de bens de uso comum e identificou que no início da segunda grave seca (2012-2013), mesmo com o sistema nacional de gerenciamento de recursos hídricos estabelecido e implantado, uma nova crise se estabeleceu e se intensificou. Foi apontado pela autora que, algumas informações apontadas como desconhecidas por aqueles autores que analisaram a primeira crise, estão presentes no plano estadual de recursos hídricos do Estado da Paraíba.

Face a esse cenário e superada a segunda grave crise do sistema em estudo, questionasse se o sistema de governança dos recursos hídricos está funcionando adequadamente, especialmente no tocante as escalas apropriadas para discutir e deliberar sobre as questões do território da bacia hidrográfica e a articulação com as partes interessadas no processo. Através dos princípios da governança da OECD, o caso de estudo será analisado e discutido a seguir.

\section{Diagnóstico da governança multinível na Gestão Urbana e dos Recursos Hídricos utilizando os princípios 1, 2, 3, 5, 7 e 9 da governança e das lacunas da OECD - Políticas}

\section{Princípio 1 - Papéis e responsabilidades}

\section{Política Estadual de Recursos Hídricos}

Na Política Nacional de Recursos Hídricos é estabelecido que a gestão dos recursos hídricos deve ser partilhada entre o Poder Público, os usuários de água e a sociedade civil (Art. 1). Também são definidas as competências do Poder Executivo Federal, Estadual e do Distrito Federal na implementação da política de recursos hídricos (Art. 29 e 30). No entanto, as competências do poder municipal/distrital são ditas de forma superficial, mesmo nas diretrizes da PNRH, sendo sinalizado que a política de recursos hídricos deve ser articulada com o uso do solo. Embora o poder municipal/distrital não seja um ator direto na gestão das águas no Brasil, é descrito que estes devem se articular com a União e Estados para realizar uma gestão dos recursos hídricos articulada com o uso do solo (Art. 3). Contudo, os papéis e responsabilidades dos atores que deveriam promover essa articulação não estão claramente definidas.

O quadro institucional do Sistema Nacional de Gerenciamento de Recurso Hídricos (SINGREH) é 
composto pelo Conselho Nacional de Recursos Hídricos, Agência Nacional de Águas, os Conselhos de Recursos Hídricos dos Estados e do Distrito Federal, os Comitês de Bacia Hidrográfica, os órgãos dos poderes públicos federal, estaduais, do Distrito Federal e municipais cujas competências se relacionem com a gestão de recursos hídricos e as Agências de Água (Art. 33).

Os objetivos do Sistema Nacional de Gerenciamento de Recursos Hídricos - SINGREH (Art. 32) são coordenar a gestão integrada das águas, arbitrar administrativamente os conflitos relacionados com os recursos hídricos, implementar a Política Nacional de Recursos Hídricos, planejar, regular e controlar o uso, a preservação e a recuperação dos recursos hídricos e promover a cobrança pelo uso de recursos hídricos.

Dessa forma, do ponto de vista da definição dos papeis e responsabilidades do quadro institucional e legal da Política Nacional de Recursos Hídricos, pode-se afirmar que os papeis e responsabilidades estão claramente definidos nas esferas federal e estadual. No entanto, no tocante a articulação proposta com a esfera municipal/distrital existe uma lacuna na Lei das Águas.

Assim, é sugerindo uma integração com as políticas urbanas (saneamento e uso do solo), e as política de meio ambiente (Art. 3), entretanto, não são determinadas as instituições responsáveis por essa articulação com o poder municipal (responsável pela gestão do uso do solo - Conforme Art. 30, da Constituição Federal de 1988), bem como os papéis e responsabilidades das mesmas, não estão descritas na política de recursos hídricos.

\section{Política Estadual de Recursos Hídricos}

A Política Estadual de Recursos Hídricos do Estado da Paraíba estabelece o Sistema Integrado de Planejamento e Gerenciamento de Recursos Hídricos composto pela Secretaria de Estado da Ciência e Tecnologia e do Meio Ambiente - SECTMA, atualmente Secretaria de Estado da Infraestrutura, dos Recursos Hídricos e do Meio Ambiente (Órgão de Coordenação), Conselho Estadual de Recursos Hídricos - CERH (Órgão Deliberativo e Normativo), Agência Executiva de Gestão das Águas do Estado da Paraíba - AESA ( Órgão Gestor) e Comitês de Bacia Hidrográfica (Órgãos de Gestão Participativa e Descentralizada) (Art. 6).

Define os papéis e responsabilidades do Conselho Estadual de Recursos e dos Comitês de Bacia Hidrográfica (Art. 10A e 10B, respectivamente). No entanto, a política deixa uma lacuna na definição dos papéis e responsabilidades da Secretaria de Recursos Hídricos e do Órgão Gestor, a AESA. Na Política Estadual de Recursos Hídricos do estado da Paraíba também é sugerido uma articulação da gestão dos Recurso Hídricos com o uso do solo (Art. 3) quando define o estabelecimento em conjunto com os municípios de um sistema de alerta e defesa civil, quando da ocorrência de eventos extremos tais como, secas e cheias.

Neste sentido, foi identificado que a diretriz trata de uma ação conjunta da gestão hídrica e dos municípios através da componente drenagem urbana, um dos serviços saneamento básico de uma cidade. Da mesma forma, é definido que no plano das bacias hidrográficas deverão conter diretrizes gerais a nível regional capazes de orientar Planos Diretores Municipais (Art. 13). Orientação também sugerida no Estatuto da cidade (Art. 42, EC). 


\section{Princípio 2 - Escalas Apropriadas}

\section{Política Nacional de Recursos hídricos}

A Política Nacional de Recursos Hídricos é assertiva ao definir a bacia hidrográfica como unidade territorial para implementação da política e do sistema de gerenciamento dos recursos hídricos (Art. 1). No entanto, se omite na definição da coordenação entre as outras escalas de interesse do recurso, especialmente a escala municipal. Na diretriz apresentada no artigo 3 da Lei das Águas, é indicado que haja integração entre as gestões dos recursos hídricos e de uso do solo, competência da gestão urbana, mas não existe um direcionamento das escalas que devem se articular, exceto a possível participação dos municípios inseridos nos limites da bacia hidrográfica.

As escalas apropriadas para à aplicação dos instrumentos da gestão dos recursos hídricos são definidas, onde os Planos de Recursos Hídricos deverão ser elaborados por bacia hidrográfica, por Estado e para o País (Art. 8), as classes de corpos de água serão estabelecidas pela legislação ambiental (Art. 10) e os valores arrecadados com a cobrança pelo uso de recursos hídricos serão aplicados prioritariamente na bacia hidrográfica em que foram gerados (Art. 22).

A política orienta que os Poderes Executivos do Distrito Federal e dos municípios deverão promover a integração das políticas locais de saneamento básico, de uso, ocupação e conservação do solo e de meio ambiente com as políticas federal e estaduais de recursos hídricos (Art. 31). Contudo, não define como essa integração deve ocorrer, ou seja, a Política define as escalas apropriadas à integração, mas se omite na definição de como a coordenação entre as diferentes escalas deverá ocorrer.

No que compete a definição da área de atuação dos Comitês de Bacia Hidrográfica, é descrito que serão a totalidade de uma bacia hidrográfica, a sub-bacia hidrográfica de tributário do curso de água principal da bacia, ou de tributário desse tributário ou grupo de bacias ou sub-bacias hidrográficas contíguas (Art. 37). As Agências de Água terão a mesma área de atuação de um ou mais Comitês de Bacia Hidrográfica (Art. 42). Neste sentido, é identificado uma lacuna relacionada a escala municipal, que com a configuração descrita, poderá ter dificuldades pois nem todos os municípios estão inseridos no comitê.

\section{Política Estadual de Recursos Hídricos}

A Política Estadual de Recursos Hídricos definiu as competências do Conselho Estadual de Recursos Hídricos e dos Comitês de bacia hidrográfica, assim como suas respectivas escalas de atuação dos órgãos no sistema de gestão (Art. 10A e 10B). No entanto, tanto as competências quanto a escala de atuação da AESA, órgão gestor dos recursos hídricos do estado não estão presentes na legislação estadual, exceto quando é destacado que o Fundo Estadual de Recursos Hídricos - FERH será administrado pela agência (Art. 23).

Outra exceção em relação a escala de atuação do órgão gestor, é que qualquer intervenção nos cursos de água ou aquífero que implique na utilização dos Recursos Hídricos, a execução de obras ou serviços que alterem o regime, a quantidade ou a qualidade dos mesmos, no âmbito da competência do Estado, depende da autorização do Órgão Gestor (Art. 15), no caso, a AESA. Desta forma, uma lacuna identificada na 
análise do princípio 2, na Política Estadual de Recursos Hídricos, é a definição de competências e escalas apropriadas para atuação do órgão gestor estadual.

\section{Princípio 3 - Coordenação entre setores}

\section{Política Nacional de Recursos hídricos}

Na política de recursos hídricos, a coordenação entre setores, especialmente entre a gestão dos recursos hídricos e o planejamento territorial e uso do solo, é sugerida em várias partes do documento, entre elas, no artigo 3, onde uma das diretrizes gerais da política aponta a articulação da gestão de recursos hídricos com a do uso do solo. No entanto, não há direcionamento no sentido de propor mecanismos de coordenação entre as políticas que sejam coerentes entre níveis de governo, por exemplo, para produção de um plano conjunto de uso e ocupação do solo de uma cidade com os recursos hídricos disponíveis.

Da mesma forma, no artigo 31, a Política Nacional de Recursos Hídricos descreve que na implementação da política deverá ser promovida a integração das políticas locais de saneamento básico, de uso, ocupação e conservação do solo e de meio ambiente com as políticas federal e estaduais de recursos hídricos, e que os Poderes Executivos do Distrito Federal e dos municípios deverão promover essa integração. Porém, como essa coordenação entre setores deve acontecer, não está descrita. Sugerindo assim, uma lacuna no tocante ao princípio 3.

\section{Política Estadual de Recursos Hídricos}

Na PERH não houve ocorrências do Princípio 3.

\section{Princípio 5 - Dados e informações}

\section{Política Nacional de Recursos hídricos}

A Política Nacional de Recursos Hídricos define o sistema de informações sobre recursos hídricos como um sistema de coleta, tratamento, armazenamento e recuperação de informações sobre recursos hídricos e fatores intervenientes em sua gestão. Assim como, determina que os dados gerados pelos órgãos integrantes do Sistema Nacional de Gerenciamento de Recursos Hídricos serão incorporados ao Sistema Nacional de Informações sobre Recursos Hídricos (Art. 25).

Em compatibilidade com o princípio 5, o Sistema Nacional de Informações sobre Recursos Hídricos tem como princípios básicos de funcionamento a descentralização da obtenção e produção de dados e informações, coordenação unificada do sistema e o acesso aos dados e informações garantidos à toda a sociedade (Art. 26). A política define ainda como objetivos do sistema (Art. 27) reunir, dar consistência e divulgar os dados e informações sobre a situação qualitativa e quantitativa dos recursos hídricos no Brasil, atualizar permanentemente as informações sobre disponibilidade e demanda de recursos hídricos em todo o território nacional e fornecer subsídios para a elaboração dos Planos de Recursos Hídricos.

O Sistema Nacional de Informações sobre Recursos Hídricos, se implementado conforme definido 
pela política, é um sistema robusto e adequado quando observado as diretrizes do princípio 5. Contudo, no tocante ao envolvimento das partes interessadas na concepção e implementação dos sistemas de informação sobre a água, é percebido uma lacuna, pois não há envolvimento de outros setores interessados na produção de dados e informações, como por exemplo, o setor de saneamento.

\section{Política Estadual de Recursos Hídricos}

Na Política Estadual de Recursos Hídricos não houve ocorrências do Princípio 5.

\section{Princípio 7 - Quadros regulatórios}

\section{Política Nacional de Recursos hídricos}

Na Política Nacional de Recursos Hídricos, o Sistema de Gerenciamento de Recursos Hídricos é composto pelo Conselho Nacional de Recursos Hídricos, Agência Nacional de Águas, Conselhos de Recursos Hídricos dos Estados e do Distrito Federal, Comitês de Bacia Hidrográfica (estadual e federal), os órgãos dos poderes públicos federal, estaduais, do Distrito Federal e municipais cujas competências se relacionem com a gestão de recursos hídricos e as Agências de Água (Art. 33).

De forma geral, o SINGREH funciona como quadro regulatório sólido no contexto da gestão dos recursos hídricos no Brasil, atendendo ao princípio 7. Todavia, o componente 'os órgãos dos poderes públicos federal, estaduais, do Distrito Federal e municipais cujas competências se relacionem com a gestão de recursos hídricos' não está claramente definido. Assim, a política deveria orientar mais claramente quem seriam esses órgãos que poderiam compor o SINGREH. Especialmente no tocante ao poder público municipal, que é o titular dos serviços de saneamento no Brasil e muitas desconhece (ou tem sua importância ignorada) pela gestão dos recursos hídricos.

\section{Política Estadual de Recursos Hídricos}

Entre os instrumentos de execução da Política estadual de Recursos Hídricos da Paraíba está o Sistema Integrado de Planejamento e Gerenciamento de Recursos Hídricos (Art. 4), composto pela Secretaria de Estado dos Recursos Hídricos, do Meio Ambiente e da Ciência e Tecnologia, Conselho Estadual de Recursos Hídricos, Agência Executiva de Gestão das Águas do Estado da Paraíba - AESA e Comitês de Bacia Hidrográfica (Art. 6), estabelecendo assim, um quadro regulatório para execução da política de recursos hídricos no estado. Entretanto, é notado que o quadro relatório definido pela legislação estadual não apresenta um quadro institucional abrangente, com por exemplo, não há instituição/órgão da esfera municipal para promoção de um planejamento integrado entre os recursos hídricos e o desenvolvimento urbano/regional.

\section{Princípio 9 - Integridade e transparência}

\section{Política Nacional de Recursos hídricos}

Na Política Nacional de Recursos Hídricos é definido que a gestão dos recursos hídricos deve ser 
descentralizada e contar com a participação do Poder Público, dos usuários e das comunidades (Art. 1). Nesse aspecto, a inclusão do usuário e das comunidades juntamente com o Poder Público reflete transparência, confiança e integridade nos processos decisórios. No estabelecimento do Sistema de Informações sobre Recursos Hídricos (Art. 25) é determinado os princípios básicos para o funcionamento (Art. 26) e os seus objetivos do Sistema (Art. 27), destacando o acesso aos dados e informações garantido à toda a sociedade e divulgar os dados e informações sobre a situação qualitativa e quantitativa dos recursos hídricos no Brasil.

É percebido que a política de recursos hídricos se pauta em práticas de integridade e transparência, tanto no seu processo de gestão como estruturação do Sistema de Informações, a fim de obter confiança nos processos de decisão. Todavia, ainda se depara com uma lacuna no tocante a responsabilização das partes interessadas, como algum ente da esfera municipal inserida nos quadros legais e institucionais que tomam as decisões na gestão dos recursos hídricos.

\section{Política Estadual de Recursos Hídricos}

Na PERH não houve ocorrências do Princípio 9. Na tabela 2 são apresentados os resultados da análise da Política Nacional de Recursos Hídricos (Lei das Águas - Lei 9.433/1997) e da Política Estadual de Recursos Hídricos (Lei nº6.308/1996 e Lei no 8.446/2007). Na tabela são apresentadas as ocorrências nas políticas de cada princípio analisado.

Tabela 2: Identificação dos Princípios da $\operatorname{OECD}(1,2,3,5,7$ e 9) na Política Nacional e Estadual de Recursos Hídricos.

\begin{tabular}{|l|l|l|l|}
\hline Princípio & Ocorrência & PNRH & PERH \\
\hline \multirow{3}{*}{$\begin{array}{l}\text { Princípio 1 } \\
\text { Papéis e responsabilidades) }\end{array}$} & Atores Responsável & Art. 1, 4, 8 e 14 & Art. 6 \\
\cline { 2 - 4 } & Papéis dos atores & Art. 29, 30,31, 35, 38 e 44 & Art. 10A e 10B \\
\cline { 2 - 4 } & Promoção da articulação & Art. 3 & Art. 3 e 13 \\
\hline \multirow{3}{*}{$\begin{array}{l}\text { Princípio 2 } \\
\text { Escalas Apropriadas) }\end{array}$} & Escalas de gestão & Art. 1,8, 22, 37 e 42 & Art. 10A e 10B \\
\cline { 2 - 4 } & Coordenação entre diferentes escalas & Art. 4, 29 e 30 & Não define. \\
\cline { 2 - 4 } & Promoção da articulação & Art. 3 e 31 & Não define. \\
\hline \multirow{3}{*}{$\begin{array}{l}\text { Princípio 3 } \\
\text { (Coordenação entre setores) }\end{array}$} & Coordenação entre setores & Art. 3 e 31 & Não define. \\
\cline { 2 - 4 } & Atores envolvidos & Não define. & Não define. \\
\cline { 2 - 4 } & Promoção da articulação & Art. 3 & Não define. \\
\hline Princípio 5 & Sistema de Informação & Art. 25, 26 e 27 & Não define. \\
\cline { 2 - 4 } & Atores responsáveis & Art. 29 e 30 & Não define. \\
\cline { 2 - 4 } & Promoção da articulação & Não define. & Não define. \\
\hline \multirow{2}{*}{$\begin{array}{l}\text { Princípio 7 } \\
\text { (Quadros regulatórios) }\end{array}$} & Definição dos quadros regulatórios & Art. 32 e 33 & Art. 10A, 10B, 22 e 23 \\
\cline { 2 - 4 } & Definição das competências & Art. 35, 38, 44 e 46 & Art. 5 \\
\cline { 2 - 4 } & Promoção da articulação & Não define. & Não define. \\
\hline $\begin{array}{l}\text { Princípio 9 } \\
\text { (Integridade e transparência) }\end{array}$ & Quadros legais e institucionais & Art. 1 & Não define. \\
\cline { 2 - 3 } & Definição das competências & Art. 25, 26 e 27 & Não define. \\
\cline { 2 - 3 } & Promoção da articulação & Não define. & \\
\hline
\end{tabular}

\section{Diagnóstico da governança multinível na Gestão Urbana e dos Recursos Hídricos utilizando os princípios da governança e das lacunas da OECD - Análise dos espaços participativos}

Princípio 4: 'Adaptar o nível de capacitação das autoridades responsáveis à complexidade dos desafios que têm de ser enfrentados no domínio da água e ao conjunto de competências que são necessárias para o desempenho das suas obrigações'.

No âmbito do comitê de bacia do Rio Paraíba, durante o período analisado (2007-2017), houve capacitação dos membros, embora introdutória, durante as cerimônias de posse das duas gestões (ATA 001, 
Comitê de Bacia Hidrográfica do Rio Paraíba; ATA 001, Comitê de Bacia Hidrográfica do Rio Paraíba). Apesar da existência de eventos de capacitação dos membros no âmbito do comitê de bacia hidrográfica, foi identificado através da análise das atas das reuniões do comitê, que a capacitação ocorrida não foi compatível com a complexidade dos desafios que precisam ser enfrentados no domínio da gestão da água. Assim como, com o conjunto de competências que são necessárias para o desempenho da função de membros de um comitê de bacia, especialmente de regiões semiáridas onde os desafios são ainda maiores.

Fato esse identificado ao longo das reuniões do comitê de bacia, onde os membros identificaram uma lacuna na capacitação e conhecimento nos assuntos colocados em pauta e em processos de deliberativos (ATA 001, Comitê de Bacia Hidrográfica do Rio Paraíba; ATA 002, Comitê de Bacia Hidrográfica do Rio Paraíba; ATA 001, Comitê de Bacia Hidrográfica do Rio Paraíba). Como destacado na primeira reunião do ano 2008 (ATA 001, Comitê de Bacia Hidrográfica do Rio Paraíba), onde um membro do Comitê da Bacia Hidrográfica do Rio Paraíba, apontou a falta de conhecimento sobre um tema colocado em votação no plenário. Naquela reunião, foi conduzido um processo de votação para o plenário, no qual iria se manifestar sobre algo sem ter o conhecimento adequado.

Neste sentido, perante o Princípio 4, no âmbito do comitê de bacia do Rio Paraíba, deve haver a promoção da capacitação dos membros do comitê compatível com o nível dos desafios enfrentados na gestão dos recursos hídricos e adaptada ao conjunto de competências necessárias para o desempenho das suas funções enquanto membro de um comitê de bacia hidrográfica.

Princípio 5: 'Produzir, atualizar e partilhar em tempo útil dados e informação consistentes, comparáveis e politicamente relevantes para as políticas da água e com ela relacionados, e usá-los para orientar, avaliar e melhorar essas políticas'.

No contexto do Comitê de Bacia Hidrográfica do Rio Paraíba, em vários momentos, dados e informações foram compartilhadas, como quando apresentado a situação pluviométrica e hidrológica na bacia hidrográfica para o ano de 2008 (ATA 002, Comitê de Bacia Hidrográfica do Rio Paraíba). A partir da análise das Atas das Reuniões, foi possível identificar a partilha de dados e informações durante a crise hídrica que acometeu a região, entre os anos de 2012 e 2017. Nesse período, os representantes das instituições gestoras das águas, como a ANA e a AESA, apresentaram informações sobre a situação do principal reservatório da bacia, o Epitácio Pessoa (ATA 001E, Comitê de Bacia Hidrográfica do Rio Paraíba). Ainda durante a crise foi apresentado ao plenário as condições pluviométricas do estado para o ano de 2016 e a ANA atualizou as informações sobre as condições do Reservatório Epitácio Pessoa no momento de crise hídrica (ATA 001, Comitê de Bacia Hidrográfica do Rio Paraíba).

Todavia, repetidamente, os membros do comitê solicitaram de compartilhamento de dados e informações. Cabe destacar, a solicitação de informações e dados sobre as alterações na bacia hidrográfica devido o futuro aporte de água fruto das obras do PISF (ATA 002, Comitê de Bacia Hidrográfica do Rio Paraíba). Assim como, a solicitação de informações e dados por membro do comitê (ATA 002, Comitê de Bacia Hidrográfica do Rio Paraíba) sobre a necessidade de incluir 'outros pontos' de pauta nas reuniões do Comitê, 'como por exemplo, informar como está o Plano de Bacia Hidrográfica do Rio Paraíba, como está a 
situação das obras de transposição do rio São Francisco que vai beneficiar a bacia do Rio Paraíba, através do seu eixo Leste, bem como será a feita a cobrança pelo uso da água transposta'. Ainda, que fosse feita apresentação de projetos submetido 'pela AESA e outras universidades com área de atuação na bacia do rio Paraíba'.

Dessa forma, sob o prisma do princípio 5, embora informações e dados sejam partilhados no âmbito do comitê, os membros expõem a necessidade de tantas outras informações e dados, inclusive para tomada de decisão e deliberação de questões de responsabilidade do comitê. De tal modo, sugere-se a promoção periódica da partilha de dados e informações envolvendo outros órgãos do SINGREH, como ANA, no tocante a gestão do reservatório Epitácio Pessoa e a AESA e Secretaria de Recursos Hídricos do Estado, para atualização permanente da situação da bacia hidrográfica.

Princípio 8: 'Promover a adoção e implementação de práticas inovadoras de governança da água por todas as autoridades responsáveis, níveis de governo e partes interessadas relevantes'.

No âmbito de práticas inovadoras de governança da água, na análise das atas das reuniões do Comitê da Bacia Hidrográfica do Rio Paraíba foram identificadas algumas ações, entre elas, a criação do Fórum em Defesa do Rio Paraíba (ATA 002, Comitê da Bacia hidrográfica do Rio Paraíba). Algumas propostas como a criação de Comissão do Planejamento de Ações do Comitê (ATA 001, Comitê da Bacia hidrográfica do Rio Paraíba). Assim como, o 'Projeto Estruturante e Sustentabilidade e Gestão em Recursos Hídricos', que tem como proposta que, as Instituições Universitárias tracem uma malha ao redor do Rio e cada instituição possa ficar responsável por um espaço para estudo e construir um banco de dados, que nortearão a Política de Recursos Hídricos (ATA 002, Comitê da Bacia hidrográfica do Rio Paraíba).

Durante o período de crise hídrica, que acometeu a região da bacia hidrográfica, os membros do Comitê sugeriram mostrar a sociedade geral a existência e a importância do Comitê para atuação mais efetiva (ATA 002E, Comitê da Bacia hidrográfica do Rio Paraíba). Segundo os membros, seria necessário 'começar o processo para mostrar a essas pessoas primeiro que o Comitê existe, e tudo o que acontece nesta bacia, tem que passar pelo plenário deste Comitê e que podemos buscar com o plenário uma convivência legal' (ATA 002E, Comitê da Bacia hidrográfica do Rio Paraíba), no sentido de promover uma aprendizagem social e facilitar diálogo com a sociedade em geral.

Dessa forma, embora exista indícios da promoção da boa governança através do Princípio 8, ainda existem lacunas como por exemplo, a promoção de formas inovadoras de cooperação para potencializar recursos e competências, aproveitando sinergias entre setores, como saneamento e recursos hídricos e uso do solo e recursos hídricos, no âmbito da gestão dos recursos hídricos com colaborações do poder municipal. E promoção da articulação entre a ciência e as políticas públicas com vista a contribuir para uma melhor governança da água.

Princípio 9: 'Generalizar práticas de integridade e transparência em todas as políticas, instituições e quadros de governança da água de forma a melhorar a responsabilização e aumentar a confiança nos processos de decisão'.

No contexto do Comitê de Bacia Hidrográfica, diante da análise do Princípio 9, foi identificado como 
práticas de integridade e transparência a discussão sobre a alteração da Lei Estadual para se adequar a Legislação Nacional. Nesse sentido, foi colocado em votação para o plenário ‘a proposta da Comissão, a qual contempla além das mudanças na Legislação Estadual de Recursos Hídricos, diversas alterações no Decreto de Cobrança pelo uso da água bruta' (ATA 002E, Comitê da Bacia hidrográfica do Rio Paraíba). Contudo, alerta-se para a necessidade da generalização de práticas de integridade e transparência a fim de aumentar a confiança nos processos de decisão, no âmbito do Comitê de Bacia Hidrográfica do Rio Paraíba. Visto que, ainda foi identificado uma considerável lacuna neste sentido.

Princípio 10: 'Promover o comprometimento das partes interessadas de forma a obter contribuições informadas e orientadas para os resultados na formulação e implementação das políticas da água'.

A promoção do comprometimento das partes interessadas nas questões da água foi identificada em vários momentos no âmbito do comitê de bacia hidrográfica. No entanto, perante a função primeira do Comitê de Bacia Hidrográfica, ser o órgão cujo a responsabilidade é discutir e deliberar, em primeira instância, as questões relacionadas aos recursos hídricos, na Bacia hidrográfica do Rio Paraíba, muitas vezes essa função foi assumida pelo Ministério Público (ATA 002E, Comitê da Bacia hidrográfica do Rio Paraíba).

Diante dessa situação, foi destacado durante as reuniões do comitê que 'atos de agressão aos recursos naturais na Bacia Hidrográfica devem ser primeiros tratados no âmbito do Comitế. Foi lembrado por membros do Plenário que 'o Comitê é um ente novo no Sistema de Gestão Hídrica do Estado, diferentemente de órgãos ambientais e o próprio Ministério Público, e que seria importante convidar este último para participar das reuniões do $\mathrm{CBH}-\mathrm{PB}^{\prime}$.

No sentido de cobrar o comprometimento das partes interessadas, o plenário do comitê de bacia promoveu ações como enviar 'a todos os membros do CBH-PB uma lista com todos os titulares e suplentes, e que da próxima reunião em diante constasse nas mensagens de convocação, a lista de membros (titulares e suplentes) do CBH-PB' (ATA 002, Comitê da Bacia hidrográfica do Rio Paraíba). Assim como, emissão de ofícios 'ao IBAMA e SUDEMA sobre essas licenças' (de retirada mecanizada de areia no leito do rio Paraíba) (ATA 001, Comitê da Bacia hidrográfica do Rio Paraíba).

Essas ações foram sugeridas após o plenário ter 'dificuldade de finalizar' uma determinada pauta e 'que há 3 reuniões está buscando obter sucesso' (ATA 002E, Comitê da Bacia hidrográfica do Rio Paraíba). Alertando assim, para falta de comprometimento das partes interessadas nas questões de água, refletindo a ausência nas reuniões do comitê de bacia, que precisa de número mínimo de membros para deliberação das questões em pauta.

Porém, em vários momentos, foram identificadas ações promovidas pelos membros, que apontam o comprometimento das partes interessadas, como a solicitação de inclusão de projetos desenvolvidos pelas instituições de ensino e pesquisa no âmbito da bacia hidrográfica constassem no Plano da Bacia do Rio Paraíba (ATA 002, Comitê da Bacia hidrográfica do Rio Paraíba).

Outro apontamento neste sentido foi a formação de comissão para análise do plano da bacia, ações de relevante importância visto que o plano é o direcionador das ações do comitê de bacia (ATA 001, Comitê 
da Bacia hidrográfica do Rio Paraíba). Da mesma forma, no tocante a transposição do Rio São Francisco, quando a Diretoria do Comitê de Bacia destacou a preocupação em relação aos planos municipais de saneamento básico, visto que a maioria dos municípios da bacia hidrográfica não havia elaborado os planos de saneamento (ATA 001, Comitê da Bacia hidrográfica do Rio Paraíba), e a falta dos mesmos implica consideravelmente na qualidade de água da bacia hidrográfica.

Durante a longa e severa crise hídrica que a região passou, entre os anos de 2012 e 2017, o comitê de bacia convidou os órgãos responsáveis e envolvidos na questão dos recursos hídricos da Bacia hidrográfica do Rio Paraíba (AESA, CAGEPA, Agência Nacional de Água - ANA, Assembleia Legislativa - Frente Parlamentar da Água, Ministério Público e os prefeitos dos oitenta e cinco municípios que compõe a bacia hidrográfica) para expor, dentro do seu domínio, a situação atual e quais as perspectivas futuras já que a seca continuava (ATA 001E, Comitê da Bacia hidrográfica do Rio Paraíba). Após as colocações, o comitê adotaria uma posição diante da situação de crise hídrica. Contudo, o Comitê de Bacia não foi 'o protagonista nas discussões sobre a questão da crise hídrica da cidade de Campina Grande (ATA 001E, Comitê da Bacia hidrográfica do Rio Paraíba). Assim como, a população da cidade, não teve o devido conhecimento da existe e do importante papel do Comitê de Bacia num contexto de crise hídrica.

Princípio 11: 'Encorajar quadros de governança da água que ajudem a gerir compromissos equilibrados entre os múltiplos usos da água, entre áreas urbanas e rurais e entre diferentes gerações'.

No âmbito do comitê de bacia, o princípio 11 foi identificado na promoção de debate com os órgãos competentes sobre os riscos da crise hídrica (ATA 001, Comitê da Bacia hidrográfica do Rio Paraíba) quando foi proposto e aprovado pelo plenário 'uma reunião extraordinária e convidar AESA, CAGEPA, Agência Nacional de Água - ANA, Assembleia Legislativa - Frente Parlamentar da Água, e Ministério Público, órgãos que são ligados a questão hídrica do Estado para que, cada um exponha dentro do seu domínio a situação atual e quais as perspectivas futuras já que a seca continua'.

Na deliberação do comitê diante dos conflitos oriundos, principalmente, da crise hídrica, entre os anos de 2012 e 2017 (ATA 003E, Comitê da Bacia hidrográfica do Rio Paraíba). Na ocasião, e diante das discussões e apresentações dos órgãos competentes, o comitê de bacia se posicionou favorável a suspensão de todos os usos, o tempo que for necessário, para instrumentalizar a operação em conjunto com a fiscalização com o objetivo de reestabelecer o abastecimento das cidades do Vale do Rio Paraíba, sendo permitido apenas os usos prioritários como, abastecimento humano e dessedentação animal'.

Dessa forma, o comitê promoveu compromissos equilibrados na tomada de decisão sobre os múltiplos usos da água num momento de escassez hídrica. Todavia, como o comitê de bacia hidrográfica não foram protagonistas nas discussões ocorridas no período de crise hídrica na região da bacia hidrográfica, necessitando assim, de ações que promovam um debate público com a sociedade sobre as questões da água, com vista a melhor orientar e participar dos processos de tomada de decisão, principalmente em momentos críticos.

Princípio 12: 'Promover uma adequada e regular monitorização e avaliação das políticas e da governança da água, partilhando os resultados com o público e fazendo ajustamentos quando necessário'. 
No contexto do comitê de bacia hidrográfica, foi identificada uma ocorrência do princípio 12, quando foi avaliada a compatibilidade entre a legislação federal e estadual (ATA 002, Comitê da Bacia hidrográfica do Rio Paraíba), no sentido de que a 'lei estadual precisava ser alterada para harmonizá-la com a lei federal de recursos hídricos'. Assim, da mesma forma que o conselho da cidade, no âmbito do comitê de bacia, é necessário o desenvolvimento de mecanismos de monitorização e avaliação das políticas de água no contexto urbano e rural, para orientar de forma eficaz a tomada de decisão assim como, partilhar dos resultados dos processos com a sociedade.

Diretrizes para gestão dos recursos hídricos e urbana para a boa governança da água no caso de estudo analisado

\section{Diretrizes para a boa governança - Falha nas políticas de Gestão dos Recursos hídricos e Urbana}

Na análise das políticas, sob o ponto de vista dos princípios 1, 2, 3, 5, 7 e 9, foi possível identificar as lacunas destacadas anteriormente e estabelecimento das seguintes diretrizes para a boa governança dos recursos hídricos, sob à luz dos princípios da governança da OECD, conforme figura 2.

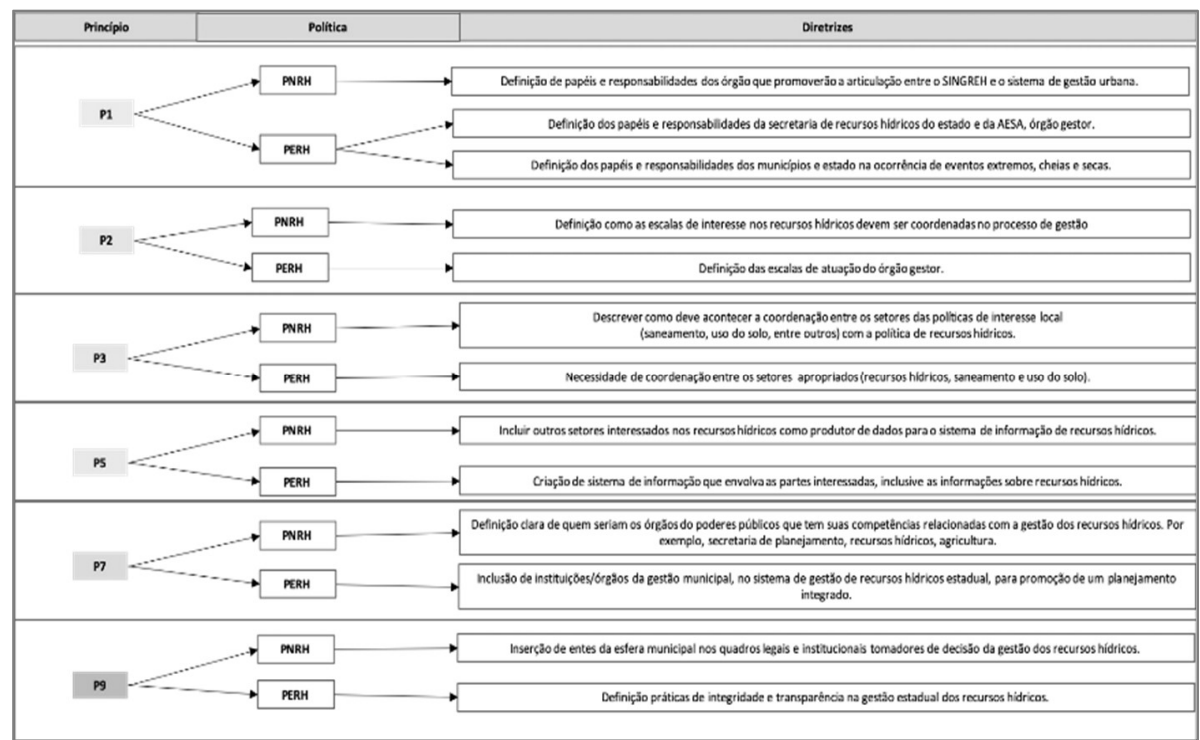

Figura 2: Diretrizes para boa governança da água - Falhas nas políticas através das análises dos princípios 1, 2, 3, 5, 7 e 9.

\section{Diretrizes para a boa governança - Falha nos Espaços Participativos da Gestão dos Recursos hídricos e Urbana}

O espaço participativo (Comitê de Bacia do Rio Paraíba) foi analisado sob o prisma dos princípios 4, $5,8,9,10,11$ e 12 e por meio das lacunas detectadas, foram determinadas diretrizes para a boa governança dos recursos hídricos, estabelecidas sob à luz dos princípios da governança da $\mathrm{OECD}$, conforme figura a seguir (Figura 3). 


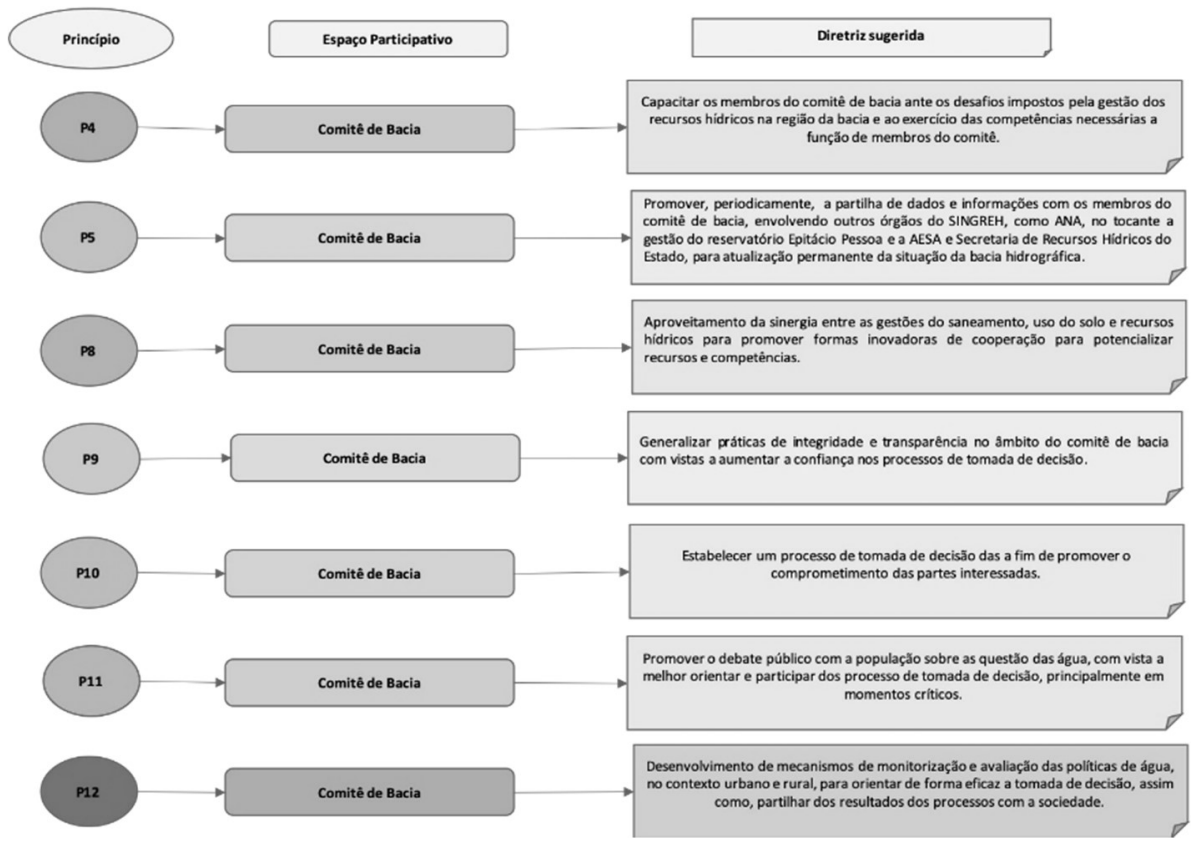

Figura 3: Diretrizes para boa governança da água - Falhas nos espaços participativos através das análises dos princípios $4,5,8,9,10,11$ e 12.

\section{CONCLUSÕES}

A análise do aparato jurídico-institucional da gestão dos recursos hídricos, através dos princípios de governança da OECD, permitiu apontar diretrizes para a boa governança dos recursos hídricos, pautadas em processos mais articulados e com o envolvimento das partes interessadas. Da mesma forma, a análise do espaço participativo, evidenciou a necessidade de ações e formas de implementação, das políticas, com atuação mais expressiva e articulada no âmbito da gestão e de todos os interesses envolvidos na tomada de decisão.

Neste sentido, procurou-se investigar como as políticas, no âmbito da gestão dos recursos hídricos, definiam os papeis e responsabilidades dos atores interessados nos recursos hídricos, se essa gestão ocorria nas respectivas escalas apropriadas e como acontecia a coordenação entre setores interessados. Investigouse ainda, se a partilha de dados e informações ocorria de forma apropriada proporcionando integridade e transparência. Por fim, se os quadros regulatórios estabelecidos pela legislação eram sólidos.

No espaço participativo, considerado como instâncias de implementação das políticas, analisou se os membros foram capacitados de acordo com os desafios que a função requeria. Se nesse espaço havia a prática de ações que apontassem para a boa governança como a partilha eficiente e consistente de dados e informações de interesse dos atores e promovendo integridade e transparência. Práticas inovadoras de governança e comprometimento das partes interessadas nas questões de deliberação dos espaços e promoção de compromisso equilibrados e monitorização e avaliação das políticas.

Com base nas análises realizadas foi possível verificar uma série de lacunas diante do processo de boa governança da água, especialmente no sentido de articular as escalas apropriadas aos desafios da gestão dos recursos hídricos. Assim, diante dos estudos realizados, verificou-se que é necessária uma definição mais clara nas políticas, das questões de articulação do território municipal com a escala de bacia hidrográfica. 0 envolvimento dos atores de diferentes escalas nos espaços de participação se torna fundamental, à medida 
que promove o diálogo e o consenso entre as demandas e disponibilidades relacionadas aos recursos hídricos, questões fundamentais para uma efetiva gestão dos recursos hídricos.

As lacunas identificadas após esse estudo, apontam para necessidade de melhores estratégias na elaboração das políticas, considerando que embora se tenham divisões políticas-administrativas diferentes, o território e os recursos são os mesmos. As tomadas de decisão, seja no âmbito da bacia ou do município, precisam ser capazes de refletir a real dinâmica do território, onde os processos ocorridos nas cidades, tem impactos significativos na dinâmica da bacia hidrográfica, requerendo assim um maior comprometimento e envolvidos dos atores de ambas as gestões.

\section{REFERÊNCIAS}

BARRON, N. J.; KULLER, M.; YASMIN, Y.; CASTONGUAY, A. C.; CONN, R. J.; COPA, V.; DUNCAN-HORNER, E.; GIMELLI, F. M.; JAMALI, B.; NIELSEN, J. S.; NOVALIA, K. N.; SHEN, P. F.; BROWN, R. R.; DELETIC, A.. Towards Water Sensitive Cities in Asia: An Interdisciplinary Journey. Water Science and Technology, London, v.76, n.4, 2017.

DOI: http://doi.org/10.2166/wst.2017.287

BROWNE, G. R.; RUTHERFURD, I. D.. The Case for Environment in All Policies: Lessons from the 'Health in All Policies' Approach in Public Health. Environmental Health Perspectives, Rockville Pike, v.125, n.2, p.149-154. DOI: http://dx.doi.org/10.1289/EHP294

CAMPOS, V. N. O.; FRACALANZA, A. P.. Governança das Águas no Brasil: Conflitos pela Apropriação da Água e a Busca da Integração como Consenso. Ambiente \& Sociedade, São Paulo, v.13, n.2, p.365-382, 2010.

GALVÃO, C. O.; REÊGO, J. C.; RIBEIRO, M. M. R.; ALBUQUERQUE, J. P. T.. Sustainability characterization and modeling of water supply management practice. In: IAHS SCIENTIFIC ASSEMBLY (REGIONAL MANAGEMENT OF WATER RESOURCES), 268. Anais. Maastrich: IAHS, 2001.

MITCHELL, D.; ENEMARKB, S. T.; VAN DER MOLEN, P. Climate resilient urban development: Why responsible land governance is importante. Land Use Policy, v.48, p.190-198, 2015. DOI: http://doi.org/10.1016/i.landusepol.2015.05.026

OECD. Governança dos Recursos Hídricos no Brasil. Paris: OECD Publishing, 2015. DOI:

http://dx.doi.org/10.1787/9789264238169-pt
RÊGO, J. C.; RIBEIRO, M. M. R.; ALBUQUERQUE, J. P. T.; GALVÃO, C. O.. Participação da sociedade na crise 1998-2000 no abastecimento d'água de Campina Grande/PB, Brasil. In: DIÁLOGO INTERAMERICANO DE GERENCIAMENTO DE ÁGUAS, 4. Anais. Foz do Iguaçu, 2001.

RÊGO, J. C.; GALVÃO, C. O.; VIEIRA, Z. M. C. L.; RIBEIRO, M. M. R.; ALBUQUERQUE, J. P. T.. Atribuições e responsabilidades na gestão dos recursos hídricos - O caso do açude Epitácio Pessoa/Boqueirão. In: SIMPÓSIO BRASILEIRO DE RECURSOS HÍDRICOS, 20. Anais. Bento Gonçalves, 2013.

RIBEIRO, M. A. F. M.. Participação Pública na gestão de recursos hídricos no Brasil e em Portugal. Tese (Doutorado em Recursos Naturais). Universidade Federal de Campina Grande, Campina Grande, 2016.

RUNHAAR, H.; DRIESSEN, P.; UITTENBROEK, C.. Towards a Systematic Framework for the Analysis of Environmental Policy Integration. Environmental Policy and Governance, v.24, n.4, p.233-246, 2014.

SERRAO-NEUMANN, S.; RENOUF, M.; KENWAY, S. J.; LOW CHOY, D.. Connecting land-use and water planning: Prospects for an urban water metabolism approach. Cities, v.60, p.13-27, 2017.

SILVA, A. C. S.. Análise institucional da governa da água para adaptação à variabilidade e mudança climática: um caso no semiárido brasileiro (1997-2013). Tese (Doutorado em Recursos Naturais) - Universidade Federal de Campina Grande, Campina Grande, 2014.

A CBPC - Companhia Brasileira de Produção Científica (CNPJ: 11.221.422/0001-03) detém os direitos materiais desta publicação. Os direitos referem-se à publicação do trabalho em qualquer parte do mundo, incluindo os direitos às renovações, expansões e disseminações da contribuição, bem como outros direitos subsidiários. Todos os trabalhos publicados eletronicamente poderão posteriormente ser publicados em coletâneas impressas sob coordenação da Sustenere Publishing, da Companhia Brasileira de Produção Científica e seus parceiros autorizados. Os (as) autores (as) preservam os direitos autorais, mas não têm permissão para a publicação da contribuição em outro meio, impresso ou digital, em português ou em tradução. 